\title{
Effectiveness of Gross Model-Based Emotion Regulation Strategies Training on Anger Reduction in Drug-Dependent Individuals and its Sustainability in Follow-up
}

\author{
Omid Massah, ${ }^{1}$ Faramarz Sohrabi, ${ }^{2}$ Yousef A'azami, ${ }^{2,}{ }^{*}$ Younes Doostian, ${ }^{1}$ Ali Farhoudian, \\ and Reza Daneshmand ${ }^{1}$
}

${ }^{1}$ Substance Abuse and Dependency Research Center, University of Social Welfare and Rehabilitation Sciences, Tehran, IR Iran

${ }^{2}$ Clinical Psychology Department, Allameh Tabataba'i University, Tehran, IR Iran

${ }^{*}$ Corresponding author: Yousef A'azami, Clinical Psychology Department, Allameh Tabataba'i University, Tehran, IR Iran. Tel: +98-2144737510, E-mail: aazami67@gmail.com

Received 2014 October 4; Revised 2015 March 3; Accepted 2015 March 4.

\begin{abstract}
Background: Emotion plays an important role in adapting to life changes and stressful events. Difficulty regulating emotions is one of the problems drug abusers often face, and teaching these individuals to express and manage their emotions can be effective on improving their difficult circumstances.

Objectives: The present study aimed to determine the effectiveness of the Gross model-based emotion regulation strategies training on anger reduction in drug-dependent individuals.

Patients and Methods: The present study had a quasi-experimental design wherein pretest-posttest evaluations were applied using a control group. The population under study included addicts attending Marivan's methadone maintenance therapy centers in 2012 2013. Convenience sampling was used to select 30 substance-dependent individuals undergoing maintenance treatment who were then randomly assigned to the experiment and control groups. The experiment group received its training in eight two-hour sessions. Data were analyzed using analysis of co-variance and paired t-test.

Results: There was significant reduction in anger symptoms of drug-dependent individuals after gross model based emotion regulation training $(\mathrm{ERT})(\mathrm{P}<0.001)$. Moreover, the effectiveness of the training on anger was persistent in the follow-up period.

Conclusions: Symptoms of anger in drug-dependent individuals of this study were reduced by gross model-based emotion regulation strategies training. Based on the results of this study, we may conclude that the gross model based emotion regulation strategies training can be applied alongside other therapies to treat drug abusers undergoing rehabilitation.
\end{abstract}

Keywords: Emotions, Anger, Drug, Drug Dependence

\section{Background}

Opiate substance abuse affects different aspects of people's biologic, mental and social lives and not only creates addiction, but negatively affects the substance abuser's socio-economic status and plays an essential role in his/ her psyche and emotions (1). Emotion plays an important role in adapting to life changes and stressful events (2). At their most basic level, emotions can be described as bio-cognitive reactions to situations that are recognized as important or challenging opportunities (3). Although emotions have biological bases, people are capable of affecting the methods with which these emotions are expressed. This ability is called emotion regulation (4). Emotion regulation is described as: a, awareness and understanding of emotions; b: accepting emotions; and c: ability to control impulsive behaviors and behaving according to desired goals to achieve personal and conditional goals (5). Based on the Gross model (2002), emotion regulation (ER) includes all conscious and subconscious strategies applied to increase, maintain and reduce the emotional, behavioral and cognitive components of an emotional response (6). Somatic and emotional awareness and acceptance of feelings and emotions are effective for emotional regulation, although this effect is less in negative emotions (7). ER is examined from two aspects: 1, ER strategies that are activated before the incidence occurs (before emotion generation and or at its onset) that interpret the condition in a way that reduces its relevant emotional responses, and 2, strategies that are activated after the incidence occurs and or after the generation of the emotion $(8,9)$. Therefore, a low ER level that roots from an inability to effectively confront emotions and to manage them plays a role in substance abuse onset $(10,11)$. The ability to manage emotions allows the individual to use appropriate resistance strategies when exposed to situations where there is a risk of substance abuse (12). The effective management of emotions is: 1 , calming down at

Copyright (C) 2016, Zahedan University of Medical Sciences. This is an open-access article distributed under the terms of the Creative Commons Attribution-NonCommercial 4.0 International License (http://creativecommons.org/licenses/by-nc/4.0/) which permits copy and redistribute the material just in noncommercial usages, provided the original work is properly cited. 
times of distress; 2 , self-control; 3, anger management; 4 , impulse control; 5 , expression of emotions at the right time and space; 6 , avoidance of continued stress, anger, and depression; 7, management of life's failures and unavoidable difficulties; 8 , preventing the over-shadowing effect of negative emotions on one's judgment and problem-solving ability; 9, enduring failure; and 10, accepting and valuing one's self (13). Gross and John (2013) (14) presented a model for the emotion regulation process on the basis of the emotion generation quality model. The primary model included five stages (onset, situation, attention, assessment, response) $(14,15)$. The Gross ER process model consists of a series of adaptive and maladaptive strategies. People with emotional problems more often use maladaptive strategies such as obsessive thinking, worrying, avoidance, and the like. The prerequisite for intervening in emotional problems is to correct or eradicate maladaptive strategies and to teach adaptive strategies $(6,14)$. Psychopathology researchers believe aggression, violent impulses, and feelings of guilt and shame are also created as a result of inadequate ER responses (16). Moreover, lack of ER can lead to problematic behaviors such as violence (17-19), which typically stems from anger. Anger has been defined in different ways. The American psychological association (APA) (2009) defines anger as a beneficial emotion that can affect inter-personal relationships and be destructive if uncontrolled (20). Anger is usually a response to un-fulfillment of one's or another's expectations, or toward behavior considered unacceptable by the self or another (21). Spielberger believed that, like anxiety, anger can be examined and measured for its state and trait (22). Spielberger defines state anger (SA) as an emotional state or condition that includes a subjective feeling of tension, offence, restlessness, resentment and rage that is associated with an autonomous nervous system. Trait anger (TA) is defined as the frequency and repetition of anger by the individual through time and situations (22, 23). Many studies have addressed the role and influence of ER on anger control. According to Szasz et al.'s results, reappraisal techniques have greater efficacy as compared to submission and suppression (inhibition) techniques in balancing the anger experience and expression (24). Another study conducted by Martin et al. (2005) shows an association between cognitive ER and depression, anxiety, stress and anger (25). Furthermore, over-regulation of emotion through increased negative affect, reduced inhibition against aggression, giving up decision-making procedures, decline of social networks and increased physiologic arousal can all lead to aggressive behavior (26). Most research studies have recognized ER strategies as the everlasting companions of negative emotions such as depression, anxiety, stress and anger (27). Therefore, taking into account the role of ER limitations in creating and sustaining emotional problems, teaching gross model-based ER skills may help reduce emotional problems like anger, thereby underscoring the significance of this and other similar studies.

\section{Objectives}

The goal of the current study was to find answers to the following questions: 1 , does teaching the gross modelbased emotion regulation method affect anger reduction in substance-dependent individuals? and 2, is the effect of the emotion regulation training sustainable on anger reduction during the follow-up period?

\section{Patients and Methods}

A quasi-experimental study was conducted with pretestposttest evaluations using a control group and random replacement. The samples were equally divided into two groups and subjected to the pre-test. One group was exposed to the test variable, and the control group received no intervention. Both groups underwent posttest evaluations.

\subsection{Study Population, Sample, and Sampling}

The population under study included all addicts (502 individuals) attending Marivan's addiction treatment and rehabilitation centers in 2012 - 2013 while they were undergoing methadone maintenance therapy. Sampling was done in two stages. In the first phase, convenience sampling was done by visiting one of Marivan's clinics accessible to the researcher. Then, simple random sampling was done to select 30 substance-dependent individuals (from 78 patients of the clinic) who were then randomly and equally assigned to the experiment and control groups.

\subsection{Inclusion and Exclusion Criteria}

Individuals were required to be male; aged between 18 and 50 years old; undergoing methadone maintenance therapy; have the DSM-IV-TR criteria of substance dependency; and have at least primary education. Individuals with severe psychiatric disorders such as psychosis, bipolar or dissociative disorders (on the basis of medical assessment) or with a physical illness that would prevent participation in the program were excluded from the study.

\subsection{The Research Process}

Gross model-based emotion regulation strategies training was given as the intervention of the study. The manual for the training has been developed by Gross et al. and is used for management and regulation of emotions $(6,14,15,28-30)$. The different stages of ER training were based on this manual and were conducted in the form of eight two-hour group sessions. First, the participants were briefed about the research project and the significance of the topic. After giving their consent to participate, they completed the Spielberger questionnaire. The participants were then randomly divided into one test and one control group. In the next stage, all the test participants were asked to participate in all of the sessions. Eventually, the intervention group received the intervention, and the control group received no training or intervention. After the 
Massah O et al.

Box 1. Summary Manual of Gross's Emotion Regulation Strategies Training Sessions

\section{Sessions}

\begin{tabular}{|c|c|}
\hline First & $\begin{array}{c}\text { Introducing the participants to each other, beginning a mutual relationship between the group leader (consultant) } \\
\text { and members, and performing exercises to become more familiar with one another. }\end{array}$ \\
\hline Second & $\begin{array}{l}\text { Recognizing emotion and arousing situations through teaching different acts of emotions, discussion of information } \\
\text { regarding different aspects of emotion and short-term and long-term effects of emotions. }\end{array}$ \\
\hline Third & $\begin{array}{l}\text { 1) Self-assessment with the goal of recognizing one's own emotional experiences; 2) self-assessment with the goal of } \\
\text { recognizing the extent of emotional vulnerability in the individual; 3) self-assessment with the goal of identifying } \\
\text { regulatory strategies. }\end{array}$ \\
\hline Fourth & $\begin{array}{l}\text { 1) Preventing social isolation and avoidance; } 2 \text { ) Teaching the problem-solving strategy;3) Teaching interpersonal skills } \\
\text { (conversation, self-expression and conflict resolution). }\end{array}$ \\
\hline Fifth & 1) Putting an end to obsessive thinking and worrying; 2 ) teaching attention. \\
\hline Sixth & 1) Identification of incorrect assessments and their impact on emotional states;2) teaching the reappraisal strategy. \\
\hline Seventh & $\begin{array}{l}\text { 1) Identification of the rate and method of applying the inhibition strategy and examining its emotional outcomes; 2) } \\
\text { confrontation; 3) teaching emotion expression; 4) behavior modification through environmental reinforcement; 5) } \\
\text { teaching emotional catharsis, relaxation and reverse action. }\end{array}$ \\
\hline Eighth & $\begin{array}{l}\text { 1) Assessing the extent of achievement of personal and group goals; } 2 \text { ) application of learned skills in the natural } \\
\text { environments outside the session; 3) examining and resolving barriers to performing assignments. }\end{array}$ \\
\hline
\end{tabular}

course concluded, both groups were evaluated (however, after the training course was conducted, and to preserve the control group's mental health, a single training session was held that had no effect on the research result). The intervention group's follow-up was completed four months after the intervention by conducting the test on the intervention group and evaluating them again $(6,14,15)$

\subsection{Data Collection Tool}

State trait anger expression inventory-2nd Edition (STAXI-2): this questionnaire was developed by Spielberger $(22,23)$. This 57 -item questionnaire includes six scales, five subscales and one anger expression indicator that give an overall measurement of anger expression and control. The first 15 questions of this test assess the anger state, and the second part that consists of ten questions measures the anger trait. The last part of this questionnaire contains 32 questions on the individual's reaction during anger and how it is expressed and controlled. Three of the five main scales of the primary draft of the questionnaire have been preserved in STAXI-2, which includes anger trait, anger expression-out and expression-in. The two AT subscales also have not changed: angry mood and angry reaction. The anger control-out scale consists of eight items, seven of which are the anger control items of the first draft of the questionnaire. The anger control-in scale consists of eight items, all of which are new items. Ten items of the primary questionnaire draft belonged to the AT scale, which has now been extended to 15 items to assess three components distinct from the severity of anger's emotional state. These three components are the feeling of anger, the urgent need to verbally express anger, and the urgent need to physically express anger. While responding to the questionnaire's 57 items, the participants rank their status on a four-degree scale, ranging from almost never
(1) to almost always (4). This questionnaire was applied by Spielberger et al. on 1,644 ordinary adults and 276 patients admitted to the psychiatric hospital. Through this project, the validity coefficients of the anger expression and anger control scales were computed, and the overall anger expression indicator was estimated at 0.82 $(22,23)$. In Iran, this test initially was standardized prim by Mokhtari (2001), and its validity coefficients were estimated at 0.60 to 0.90 (31). It then was normalized by Khodayarifard et al. and its validity coefficients were estimated at 0.72 to 0.93 (32). Oraki (2011) computed the validity coefficients at 0.70 to 0.85 (33). Using Cronbach's alpha, the validity coefficient calculated in this study was estimated at 0.88 .

\section{Results}

The participants of the study were in the age range of 22 - 49 years, with a mean age of $31.37 \pm 6.76$ years. $33.3 \%$ were old system sixth graders, $53.3 \%$ were high school graduates, $10 \%$ had a bachelor's degree and higher. $36.7 \%$ were single, $46.7 \%$ were married and $13.3 \%$ were divorced. $43.3 \%$ used opioids and 53.3\% used stimulants. To evaluate the difference between the two groups, after presenting the independent variable univariate, analysis of covariance (ANCOVA) was used.

The proposals of ANCOVA have been done. In other words, to use ANCOVA and to show the equivalence of the intervention group's and control group's variances in the pretest stage, and equivalence of regression curve or slopes, Levene's F test and Kolmogorov-Smirnov tests were used. As shown in Table 1, the presumption of equality of the regression slope or curve and variance equivalences of the test and control groups have been approved. Table 2 shows the mean and standard deviations of the test and control groups through pretest, posttest and follow-up. 
Massah O et al.

\begin{tabular}{lccc}
\hline Table 1. Levene and Kolmogorov-Smirnov Test for the Validity of the ANCOVA Model for Anger ER Training \\
\hline & $\mathbf{F}$ & $\mathbf{Z}$ & Level of Significance \\
\hline Levene's Test & 1.994 & NA & 0.169 \\
Kolmogorov-Smirnov Test & NA & 1.052 & 0.219 \\
\hline
\end{tabular}

Abbreviation: NA, not available.

\begin{tabular}{lcc}
\hline Table 2. The Mean and Standard Deviations of the Test and Control Groups Through Pretest, Posttest and Follow-up \\
\hline Stage & Intervention Group & Control Group \\
\hline Pretest & $143 \pm 18.28$ & $141.5 \pm 24.50$ \\
Posttest & $132.4 \pm 18.20$ & $142.2 \pm 21.94$ \\
Follow-up & $126.8 \pm 5.56$ & NA \\
\hline
\end{tabular}

Abbreviation: NA: not available.

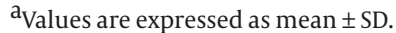

Table 3. Summarized Results of ANCOVA of the Anger Variable in the Test and Control Groups After Holding the Sessions

\begin{tabular}{lccc}
\hline Source & FCoefficient & Statistical Power & P Value \\
\hline Pretest & 13.58 & 0.944 & 0.001 \\
Group membership & 2.58 & 0.341 & 0.001 \\
\hline
\end{tabular}

Table 4. T Correlation Test for Investigating the Sustainability of the ER Training on the Anger Variable During Follow-up

\begin{tabular}{lccccc}
\hline Stage & Mean \pm SD & Mean Standard Error & t Value & df & P Value \\
\hline Posttest & $140.32 \pm 18.20$ & 4.69 & 1.064 & 14 & 0.305 \\
Follow-up & $126.87 \pm 5.56$ & 1.43 & 1.064 & 14 & 0.305 \\
\hline
\end{tabular}

According to Table 2, the mean of the intervention group decreased in the posttest as compared to the control group. This reduction also was evident during the follow-up period. Table 3 shows the results of ANCOVA of the anger variable in the test and control groups.

Table 3 shows that after controlling the impact of the pretest, significant differences were observed between the mean anger scores of the test and control groups ( $P$ $<0.001)$. Moreover, a major portion of the anger variance (0.091) in the posttest was related to the effect of the ER training. The statistical power was greater than 0.8 , which shows the adequacy of the sample size. Generally speaking, the results show that ER training can prove effective in reducing anger symptoms in substance-dependent individuals. To investigate the sustainability of the ER training on the criteria variables in the follow-up period, a paired sample t-test was used, the results of which are presented in Table 4 .

The results of Table 4 show no significant differences between posttest and follow-up in the intervention group. Therefore, the effect of the anger reduction ER training was sustainable in the participants, which affirms the hypothesis of the study regarding the effectiveness of ER training on anger reduction in the follow-up period $(\pi>$ $0.05, \mathrm{t}=1.064$ ).

\section{Discussion}

In this study, the effectiveness of gross model-based emotion regulation strategies training in anger reduction was evaluated in substance-dependent individuals. The results show that ER training can reduce the level of anger in substance-dependent individuals. Szasz et al. found that reappraisal techniques had greater effectiveness as compared to submission and suppression (inhibition) in balancing the anger experience and expression (24). However, other studies have shown the effectiveness of different approaches. For example, Narimani et al. showed that acceptance or commitment and emotion regulation training were effective in reducing high-risk behaviors of students with dyscalculia (34). Another study conducted by Martin and Dahlen (2005) shows an association between cognitive ER and depression, anxiety, stress and anger (25). Furthermore, overregulation of emotion through increased negative affect, reduced inhibition against aggression, giving up decision-making procedures, decline of social networks and increased physiologic arousal can all lead to aggressive behavior (26). Fathi and Merabizade Honarmand (2008) also arrived at the same conclusion, that aggressiveness is one of the predisposing factors of opioid drug abuse (35). On the whole, research shows that those who cannot control their arousal probably will become permanent drug abusers (36). On the other hand, many studies have shown that substance abusers have difficulty regulating their emotions, and or their negative emotional state hastens their substance abuse $(37,38)$. 
Based on research results, it may be said that substancedependent individuals are less capable of enduring failure because of their mood traits. Based on the frustration-aggression hypothesis, failure to achieve one's goals or desires most probably leads to aggressive behavior. Therefore, these individuals apply substance abuse as an avoidance-based coping strategy albeit a negative and inefficient one to reduce their problems. Some substance abusers use substances to alleviate their stress and to reduce their aggressive feelings (39). According to Fox et al.'s studies, cocaine-dependent individuals (CDI) exhibit outstanding defects in ER, which is associated with more stressful reactions and reduced impulse control $(40,41)$. Many of the therapies recommended for anxiety, eating and substance abuse disorders include the reduction of maladaptive ER methods and the increase of adaptive ER methods. Establishing a relationship between various ER methods and psychiatric disorders can make current psycho-social therapeutic methods more effective. Moreover, it can guide the time of application of each method as well as the selection of the preferred method $(28,42$, 43). Lack of control of anger is the basis for many individual and social problems. Therefore, the expression of this emotion requires correct management and control, which, if realized, can have beneficial effects on improving one's behavior $(44,45)$. The gross model-based emotion regulation training can reduce symptoms of anger in drug-dependent individuals. Based on the results of this study, we may conclude that the gross model-based emotion regulation training can be applied alongside other therapies to treat drug abusers undergoing rehabilitation. On the whole, difficulty regulating emotions is one of the problems drug abusers often face, and it can lead to failure to manage emotional and affect states. This study is about opioid-addicted patients, and the studied sample includes patients undergoing methadone maintenance therapy. Therefore, the generalizability of the results to other addictions and treatments is limited. Lack of follow-up in the control group, the time limit for providing education, and lack of control associated with pre-test effects are among the other limitations of the present study. It is suggested that future research should consider these issues and investigate the intervention effect on other patients, such as addicts undergoing the abstinence-based method. We recommend that other researchers compare cognitive behavior therapy (CBT) and acceptance and commitment therapy (ACT) approaches in emotion regulation and anger control or reduction. Also, we recommend that substance abuse rehabilitation centers hold workshops and or include the following concepts in their rehabilitation therapies: patients can be familiarized with the concepts of emotions, different types of emotions, methods of expression and control, and identification of emotion-arousing situations to better adapt to their environment, and also to prevent their reverting to drug abuse upon experiencing unpleasant emotions.

\section{Acknowledgments}

We thank all the individuals who participated in this research. We also extend our thanks to the clinics that cooperated in the research.

\section{Footnote}

Authors' Contribution:Yousef A'azami conducted the emotion regulation strategies training and drafted the prewriting; Faramarz Sohrabi designed and supervised the research; Omid Massah developed the literature review and discussion, analyzed data, and translated the article. The others helped first author.

\section{References}

1. Zahed A, Ghalilo K, Abolghasemi A, Narimani M. The relationship between emotion regulation strategies and interpersonal behavior among substance abusers. Research on Addiction. 2009;3(11):99-114.

2. Vanderhasselt MA, Koster EH, Onraedt T, Bruyneel L, Goubert L, De Raedt R. Adaptive cognitive emotion regulation moderates the relationship between dysfunctional attitudes and depressive symptoms during a stressful life period: A prospective study. J Behav Ther Exp Psychiatry. 2014;45(2):291-6. doi: 10.1016/j. jbtep.2014.01.003. [PubMed: 24553342]

3. Garnefski N, Van Den Kommer T, Kraaij V, Teerds J, Legerstee J, Onstein E. The relationship between cognitive emotion regulation strategies and emotional problems: Comparison between a clinical and a non-clinical sample. Eur J Pers. 2002;16(5):403-20. doi:10.1002/per.458.

4. Thompson RA. Emotion regulation: A theme in search of definition. Monogr Soc Res Child Dev. 1994;59(2-3):25-52. [PubMed: 7984164]

5. Gratz KL, Roemer L. Multidimensional assessment of emotion regulation and dysregulation: Development, factor structure, and initial validation of the difficulties in emotion regulation scale. J Psychopathol Behav Assess. 2004;26(1):41-54. doi:10.1023/b: joba.0000007455.08539.94.

6. Gross JJ. Emotion regulation: affective, cognitive, and social consequences. Psychophysiology. 2002;39(3):281-91. [PubMed: 12212647]

7. Smoski MJ, Keng S, Ji JL, Moore T, Minkel J, Dichter GS. Neural indicators of emotion regulation via acceptance versus reappraisal in remitted major depressive disorder. Soc Cogn Affect Neurosci. 2015:nsv003.

8. Ghorbany T, Mohamad Khany S, Saramy G. The comparison of effectiveness of cognitive-behavioral group therapy based on coping skills and methadone maintenance treatment in improvement of emotional regulation strategies and relapse prevention. Addiction. 2011;5(17):59-74.

9. Winterheld HA. Calibrating use of emotion regulation strategies to the relationship context: An attachment perspective.J Abnorm Soc Psychol. 2015:12165. doi: 10.1111/jopy.12165.

10. Parker JDA, Taylor RN, Eastabrook JM, Schell SL, Wood LM. Problem gambling in adolescence: Relationships with internet misuse, gaming abuse and emotional intelligence. Pers Individ Dif. 2008;45(2):174-80. doi:10.1016/j.paid.2008.03.018.

11. Hopwood CJ, Schade N, Matusiewicz A, Daughters SB, Lejuez CW. Emotion regulation promotes persistence in a residential substance abuse treatment. Subst Use Misuse. 2015;50(2):251-6. doi: 10.3109/10826084.2014.977393. [PubMed:25404467]

12. Trinidad DR, Johnson CA. The association between emotional intelligence and early adolescent tobacco and alcohol use. Pers Individ Dif. 2002;32(1):95-105. doi:10.1016/s0191-8869(01)00008-3.

13. Lynn C, Thompson RA. SOS Help for Emotions: Managing Anxiety, Anger and Depression. Tabalvor Publication; 2008.

14. Gross JJ, John OP. Individual differences in two emotion regulation processes: Implications for affect, relationships, and well- 
being. J Abnorm Soc Psychol. 2003;85(2):348-62 doi: 10.1037/00223514.85.2.348.

15. Gross JJ, Thompson RA. Emotion regulation: Conceptual foundations. Second ed ed. Guilford Press; 2011. pp. 3-26.

16. Sandler IN, Tein JY, West SG. Coping, stress, and the psychological symptoms of children of divorce: a cross-sectional and longitudinal study. Child Dev. 1994;65(6):1744-63. [PubMed: 7859552]

17. Dillon DG, Ritchey M, Johnson BD, LaBar KS. Dissociable effects of conscious emotion regulation strategies on explicit and implicit memory. Emotion. 2007;7(2):354-65. doi:10.1037/1528-3542.7.2.354. [PubMed: 17516813]

18. Miles SR, Menefee DS, Wanner J, Teten Tharp A, Kent TA. The Relationship Between Emotion Dysregulation and Impulsive Aggression in Veterans With Posttraumatic Stress Disorder Symptoms. Interpers Violence. 2015. doi: 10.1177/0886260515570746. [PubMed: 25681165]

19. Kuo C, Johnson J, Rosen RK, Wechsberg W, Gobin RL, Reddy MK, et al. Emotional dysregulation and risky sex among incarcerated women with a history of interpersonal violence. Women Health. 2014;54(8):796-815. doi:10.1080/03630242.2013.850143. [PubMed: 24965256]

20. Stearns CZ, Stearns PN. Anger: The struggle for emotional control in America's history. University of Chicago Press; 1989.

21. Power MJ, Tarsia M. Basic and complex emotions in depression and anxiety. Clinical Psychology \& Psychotherapy. 2007;14(1):19-31. doi:10.1002/cpp.515.

22. Spielberger C. Job stress survey. Wiley Online Library; 2010. pp. 1698-700.

23. Spielberger C, Sydeman SJ. State-trait anxiety inventory and statetrait anger expression inventory. Lawrence Erlbaum Associates;1994.

24. Szasz PL, Szentagotai A, Hofmann SG. The effect of emotion regulation strategies on anger. Behav Res Ther. 2011;49(2):114-9. doi: 10.1016/j.brat.2010.11.011. [PubMed: 21185551]

25. Martin RC, Dahlen ER. Cognitive emotion regulation in the prediction of depression, anxiety, stress, and anger. J Abnorm Soc Psychol.2005;39(7):1249-60. doi:10.1016/j.paid.2005.06.004

26. Roberton T, Daffern M, Bucks RS. Emotion regulation and aggression. Aggress Violent Behav. 2012;17(1):72-82. doi: 10.1016/j. avb.2011.09.006

27. Garnefski N, Kraaij V. Relationships between cognitive emotion regulation strategies and depressive symptoms: A comparative study of five specific samples. Pers Individ Dif. 2006;40(8):165969. doi:10.1016/j.paid.2005.12.009.

28. Aldao A, Nolen-Hoeksema S, Schweizer S. Emotion-regulation strategies across psychopathology: A meta-analytic review. Clin Psychol Rev. 2010;30(2):217-37. doi: 10.1016/j.cpr.2009.11.004 [PubMed: 20015584]

29. Gross JJ, Munoz RF. Emotion Regulation and Mental Health. Clin Psychol Rev. 1995;2(2):151-64. doi: 10.1111/j.1468-2850.1995. tb00036.x.

30. Gross JJ, Thompson RA. Emotion regulation: Conceptual foundations. Guilford Press; 2007. pp. 3-24

31. Mokhtari F. Investigation of psychometric properties of Spielberger's state-traite anger expression inventory-2 among 20-29 years students of Isfahan. Tarbiat Mo'allem University;; 2001.

32. Khodayarifard M, Gholamali LM, AKBARI ZS, Liaghat S. Psychometric properties of spielberger's state-trait anger expression inventory-2 among of iranian students. Tarbiat Mo'allem University; 2001.

33. Oraki M. Study of relationship between anger, self-efficiency, coping styles, tendency to narcotic drug in a group of clients dependent to narcotic drugs. Addiction. 2011;5(18):39-54.

34. Narimani M, Abbasi M, Abolghasemi A, Ahadi B. The effectiveness of training acceptance / commitment and training emotion regulation on high-risk behaviors of students with dyscalculia Int J High Risk Behav Addict. 2013;2(2):51-8. doi:10.5812/ijhrba.10791. [PubMed: 24971275]

35. Fathi K, Merabizade Honarmand M. A survey of depression, sensation seeking, aggression, attachment styles and Education of parent as predictors of drug dependency among Ahwaz teenage boys. Studies in Education and Psychology. 2008;9(2):23-46.

36. Doran N, McChargue D, Cohen L. Impulsivity and the reinforcing value of cigarette smoking. Addict Behav. 2007;32(1):90-8. doi: 10.1016/j.addbeh.2006.03.023. [PubMed:16675149]

37. Dimeff LA, Koerner K, Woodcock EA, Beadnell B, Brown MZ, Skutch JM, et al. Which training method works best? A randomized controlled trial comparing three methods of training clinicians in dialectical behavior therapy skills. Behav Res Ther 2009;47(11):921-30. [PubMed:19695562]

38. Habil MH, Abd Rashid R, Sulaiman AH, Peters H, Ahmad Zahari MM, Amer Nordin AS, et al. Substance abuse and violence behavior. Int J Addict. 2011;1(1):1-5.

39. Kittleson MJ, Carver VC. The purpose of health fairs as perceived by university-based health educators. Health Values.1990;14(4):38. [PubMed: 10107079]

40. Fox HC, Axelrod SR, Paliwal P, Sleeper J, Sinha R. Difficulties in emotion regulation and impulse control during cocaine abstinence. Drug Alcohol Depend. 2007;89(2-3):298-301. doi: 10.1016/j. drugalcdep.2006.12.026. [PubMed:17276626]

41. Fox HC, Bergquist KL, Casey J, Hong KA, Sinha R. Selective cocainerelated difficulties in emotional intelligence: relationship to stress and impulse control. Am J Addict. 2011;20(2):151-60. doi: 10.111//j.1521-0391.2010.00108.x. [PubMed: 21314758]

42. Berking M, Ebert D, Cuijpers P, Hofmann SG. Emotion regulation skills training enhances the efficacy of inpatient cognitive behavioral therapy for major depressive disorder: a randomized controlled trial. Psychother Psychosom. 2013;82(4):234-45. doi: 10.1159/000348448. [PubMed: 23712210]

43. Hofmann SG, Sawyer AT, Fang A, Asnaani A. Emotion dysregulation model of mood and anxiety disorders. Depress Anxiety. 2012;29(5):409-16. doi:10.1002/da.21888. [PubMed:22430982]

44. Aldao A. The Future of Emotion Regulation Research: Capturing Context. Perspect Psychol Sci. 2013;8(2):155-72. doi: 10.1177/1745691612459518. [PubMed: 26172497]

45. Aldao A, Nolen-Hoeksema S. When are adaptive strategies most predictive of psychopathology? J Abnorm Psychol. 2012;121(1):27681. doi:10.1037/a0023598. [PubMed: 21553934] 